\title{
Amazon river dolphins Inia geoffrensis are on the path to extinction in the heart of their range
}

\author{
A. R. MARTin and V. M. F. Da Silva
}

\begin{abstract}
Riverine cetaceans are threatened globally by increasing anthropogenic impacts, and the Yangtze river dolphin Lipotes vexillifer is already extinct. The Amazon river dolphin Inia geoffrensis is widely distributed, but is categorized as Endangered on the IUCN Red List. Drowning in gillnets and being hunted for fish bait are probably the main causes of its decline. A long-term (25-year) study of the biology and ecology of I. geoffrensis in and near the Mamirauá Reserve in Amazonas state, Brazil, has produced estimates of survival and reproductive rates based on the individual recognition of $>650$ animals. Concurrently, monthly standardized counts of dolphins along a fixed transect in the Reserve over 22 years demonstrated a sustained, profound decline. In this study we tested whether the measured rate of population decline is consistent with population parameters estimated from independent data, using population viability analysis. With the known parameters as input, programme Vortex predicted population extinction in all scenarios and a $95 \%$ loss of dolphins within 50 years. With default parameters, the model predicted a $5.5 \%$ annual decline, which is consistent with that observed. We conclude that the Amazon river dolphin population is in severe decline because of human pressures, even in one of the better protected parts of its range. Unless the accidental and deliberate killing of this species is rapidly reduced, it is highly likely that the Amazon river dolphin will follow its Yangtze counterpart to extinction.
\end{abstract}

Keywords Amazon river dolphin, Brazil, Endangered species, extinction, fishery interactions, Inia geoffrensis, population viability analysis

\section{Introduction}

D iver-dwelling cetaceans are particularly vulnerable to Rhuman pressures in many forms because they cannot escape them. Almost everywhere they live, river dolphins are subject to frequent and persistent anthropogenic threats, including chemical pollution, fragmentation of waterways,

A. R. Martin (Corresponding author, (D) orcid.org/0000-0003-1158-6919) Centre for Remote Environments, University of Dundee, Perth Road, Dundee DD1 4DY, UK. E-mail boto@live.co.uk

V. M. F. DA Silva (1D orcid.org/0000-0002-1774-0393) Instituto Nacional de Pesquisas da Amazônia, Manaus, Brazil

Received 27 July 2020. Revision requested 14 October 2020.

Accepted 7 December 2020. First published online 25 October 2021. reduced availability of food resources because of fishing and damming, hunting, and accidental entrapment in fishing nets (Reeves \& Martin, 2018). Consequently, the Yangtze river dolphin Lipotes vexillifer was the first cetacean to be rendered extinct by humans (Turvey et al., 2007), and the remaining two taxa of river dolphins in Asia, Platanista gangetica and Platanista minor, are now categorized as Endangered on the IUCN Red List (Braulik et al., 2012; Smith et al., 2012).

In South America, the boto or Amazon river dolphin Inia geoffrensis is also categorized as Endangered (da Silva et al., 2018b). The species has a wide geographical distribution that extends from the Andes to the Atlantic, including hundreds of rivers with varying levels of connectivity in Brazil, Colombia, Ecuador, Bolivia and Venezuela. Some of the more isolated populations have evolved distinct characteristics that may justify recognition as separate species or subspecies. Although the detailed taxonomy of the Amazon river dolphin is not yet resolved, it is certain that there is not one homogenous meta-population (Gravena et al., 2014; Hrbek et al., 2014; Siciliano et al., 2016).

A continuous 25-year study of botos in and near the Mamirauá Reserve, Amazonas state, Brazil (Fig. 1), has resulted in estimates of key reproductive parameters and annual survival rates (Mintzer et al., 2013; Martin \& da Silva, 2018). Data from the Reserve show a prolonged and steep population decline (da Silva et al., 2018a), probably driven by harmful fishery practices. These practices are widespread, and pressures outside the Reserve could be worse, not only because regulations applicable within the Reserve may offer some protection, but because some threats (e.g. damming and gold mining) have no known impact in the Mamirauá region (da Silva et al., 2018a).

Estimates of the key reproductive parameters (Martin \& da Silva, 2018) and survival rates (Mintzer et al., 2013) of botos from Mamirauá provide an opportunity to test whether these population characteristics are consistent with the decline in animal numbers observed during 1994-2017 (da Silva et al., 2018a).

\section{Study area and species}

We collected data in an area of seasonally flooded lowland forest, and in the rivers that drain this landscape, one of which is the mainstem of the Amazon River (Fig. 1). The focus of the work was the Mamirauá Sustainable Development Reserve, Amazonas state, Brazil. 


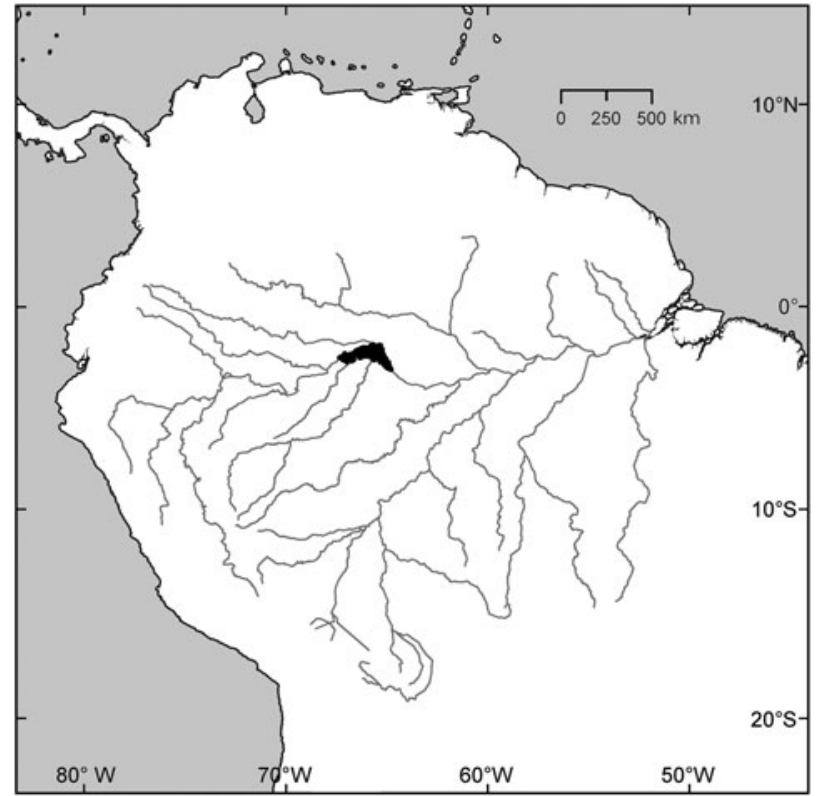

FIG. 1 Northern South America, with the Amazon River and its main tributaries. The study area, the Mamiraua Sustainable Development Reserve, is shown in black.

Even the most resident of the botos occurring in the Mamirauá Reserve were often not observed for several consecutive months, and some animals were not recorded for several years before returning. Trained observers were on the water for 7 hours nearly every day throughout the year, thus any marked individual not observed for several weeks was probably absent from the study area, which has a diameter of c. $90 \mathrm{~km}$ and an area of $>6,000 \mathrm{~km}^{2}$. Botos marked in Mamirauá were routinely encountered tens of $\mathrm{km}$ away from the Reserve, and the prolonged absence of some individuals suggests that they range over an extensive area. This is supported by data obtained via satellite tracking of Amazon river dolphins in Brazil, Colombia and Bolivia, which demonstrated that the animals routinely move tens or hundreds of km (Mosquera Guerra et al., 2018). Botos occurring within the Mamirauá Reserve on any particular day therefore represent a sample of a population that ranges over at least tens of thousands of $\mathrm{km}^{2}$ of the Brazilian Amazon.

\section{Methods}

We used Vortex 10.3.5.7 (Lacy \& Pollak, 2017) to predict population trajectories using reproductive and survival data collected in and near the Mamirauá Reserve during 1994-2018 (Mintzer et al., 2013; Martin \& da Silva, 2018). Vortex is a Monte Carlo simulation package that models the effects of deterministic factors and demographic, environmental and genetic stochasticity on population dynamics. We used 1,000 model runs (Lacy et al., 2015) in each of six scenarios that differed only in the value for the annual
TABLE 1 Input values for the Vortex model. All values derive from the authors' long-term study of $>650$ marked animals in and near the Mamirauá Reserve, Amazonas state, Brazil.

\begin{tabular}{|c|c|c|}
\hline Parameter & Value & Source \\
\hline $\begin{array}{l}\text { Age at first offspring } \\
\text { (females; years) }\end{array}$ & 10 & Martin \& da Silva (2018) \\
\hline $\begin{array}{l}\text { Age of first offspring } \\
\text { (males; years) }\end{array}$ & 13 & da Silva (1994) \\
\hline $\begin{array}{l}\text { Max. age of reproduction } \\
\text { (both sexes; years) }\end{array}$ & 40 & Authors' unpubl. data \\
\hline Max. lifespan (years) & 50 & Authors' unpubl. data \\
\hline $\begin{array}{l}\text { Max. number of broods } \\
\text { per year }\end{array}$ & 1 & Martin \& da Silva (2018) \\
\hline $\begin{array}{l}\text { Max. number of progeny } \\
\text { per brood }\end{array}$ & 1 & Martin \& da Silva (2018) \\
\hline Sex ratio at birth & $1: 1$ & Authors' unpubl. data \\
\hline $\begin{array}{l}\text { Duration of offspring } \\
\text { dependency (years) }\end{array}$ & 3 & Martin \& da Silva (2018) \\
\hline Mating system & Polygyny & Authors' unpubl. data \\
\hline$\%$ adult females breeding & 90 & Authors' unpubl. data \\
\hline $\begin{array}{l}\% \text { adult females giving } \\
\text { birth per year }\end{array}$ & 22 & Martin \& da Silva (2018) \\
\hline $\begin{array}{l}\text { Default annual survival } \\
\text { rate }\end{array}$ & $89 \%$ & Mintzer et al. (2013) \\
\hline
\end{tabular}

survival rate (three options) and whether or not breeding depression was assumed at low population numbers (two options: yes or no). A stable age distribution was assumed for all models. For the survival rate we used the estimate for this population of $89 \%$ from Mintzer et al. (2013) and two more conservative but plausible values of 88 and $86 \%$. Model runs assumed that all input parameters remain constant over time, and predicted the boto population size over a period of 200 years (Lacy et al., 2015), which represents $>9$ generations (Moore et al., 2018). The current population size of the species is not known. For the simulation we set the initial population size at 50,000, and defined extinction as the point when one sex was eliminated. No additional harvest of river dolphins was added to the model. Carrying capacity was assumed to be considerably greater than the initial population size. To be conservative, no inbreeding depression was allowed for, and the Allee parameter (A) and steepness parameter (B) were set to default values of 1.0 and 2.0, respectively (Lacy et al., 2015). Input parameters for the model are shown in Table 1 . In simulations 1-3, no allowance was made for possible density-dependent impacts on breeding. In simulations $4-6$, the assumption was made that the percentage of animals involved in breeding is reduced to $50 \%$ when the population is severely depleted.

\section{Results}

Outputs of the model runs are shown in Table 2. The year of population extinction was conservatively defined as the 
TABLE 2 Results of model runs. The values in the bottom three rows represent the number of years from the start of the model run when the stated condition was reached. For example, in Simulation 4 the model predicted that $1 \%$ of the starting population would remain after 50 years.

\begin{tabular}{lllllll}
\hline & Simulation 1 & Simulation 2 & Simulation 3 & Simulation 4 & Simulation 5 & Simulation 6 \\
\hline Annual survival rate (\%) & 89 & 88 & 86 & 89 & 88 & 86 \\
Breeding depression at low numbers? & No & No & No & Yes & Yes & Yes \\
5\% of starting population size & Year 45 & Year 38 & Year 30 & Year 34 & Year 29 & Year 24 \\
1\% of starting population size & Year 68 & Year 59 & Year 46 & Year 50 & Year 46 & Year 38 \\
Probability of extinction $=95 \%$ & Year 165 & Year 141 & Year 110 & Year 121 & Year 108 & Year 88 \\
\hline
\end{tabular}

point at which $95 \%$ of model iterations predicted extinction. This value is little affected by the estimated initial population size; in Simulation 1 (Table 2) it increases from year 165 to year 173 of the model run (a $5 \%$ difference) when initial population size is doubled to 100,000 . Because the current population size is not known, thresholds of low population levels were expressed as percentages of original population size (5 and $1 \%$ ).

Figure 2 illustrates the variation in predicted population size over 120 years when the model is run 1,000 times. In this scenario, annual survival is set at $89 \%$ and no corrections are made for depressed breeding at low population levels (i.e. as represented in Simulation 1).

Figure 3 shows the estimated mean and standard deviation of population size over time in Simulations 1 and 3 (Table 2). The two curves illustrate the range of results obtained from the 6 simulation runs. The upper curve (Simulation 1) is based on published data from the Mamirauá study (Mintzer et al., 2013; Martin \& da Silva, 2018) and shows the likely population trend if conditions for dolphins do not worsen with time.

\section{Discussion}

The annual rate of population decline predicted by the model with default input (Simulation 1) was $5.5 \%$. This is similar to the average $5.48 \%$ annual decline of botos observed over 22 years (da Silva et al., 2018a). Our findings demonstrate that three independent data sources (standardized counts, estimates of survival of marked animals and estimates of reproductive parameters) lead to the same conclusion. In this population, fewer botos are being recruited into the breeding population than are being removed from it, and the consequent decline is rapid and persistent (Figs 2 \& 3). In each of the six simulation scenarios (Table 2 ), all of which make the optimistic and perhaps unrealistic assumption that environmental conditions will not become less suitable for this species, the initial population is reduced by at least $95 \%$ in $<50$ years.

Although the observed and predicted rates of population change are consistent, and it is therefore reasonable to assume that the model is working with accurate input

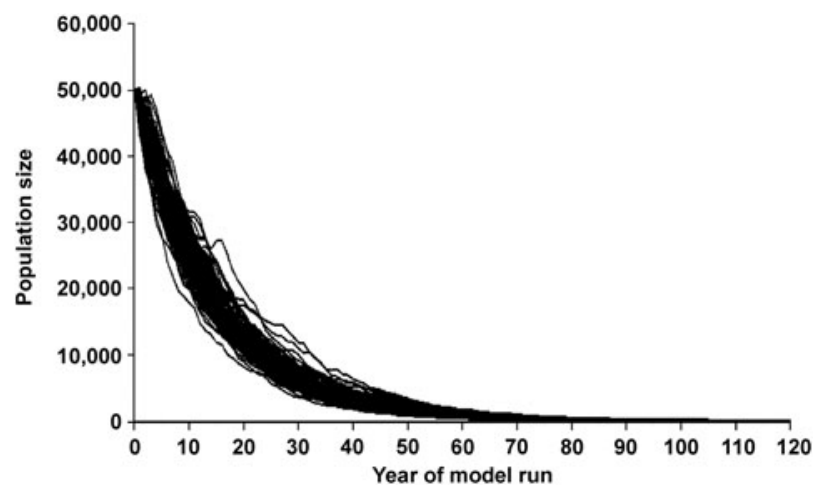

FIG. 2 Predicted population size of the Amazon river dolphin Inia geoffrensis over 120 years when the starting population is 50,000, the survival and reproductive rates are as published by Mintzer et al. (2013) and Martin \& da Silva (2018), and no corrections are made for depressed breeding at low population levels (as represented in Simulation 1). This graph illustrates the variation in predicted values generated by the Vortex package over 1,0oo model runs.

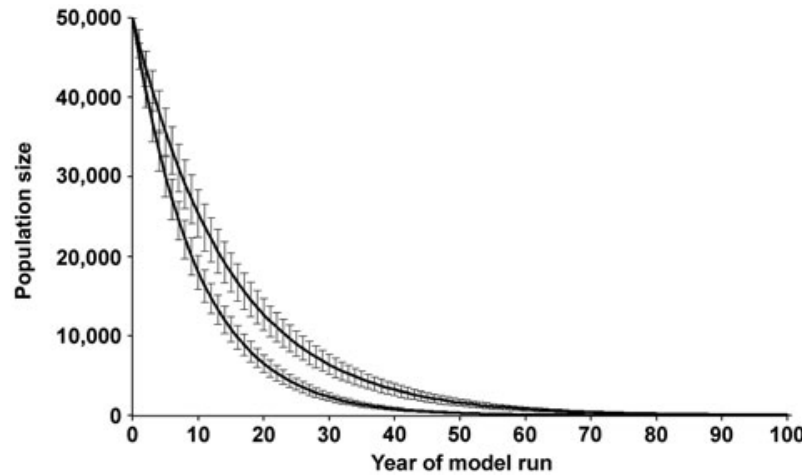

FIg. 3 Predicted population size of the Amazon river dolphin over 100 years, with annual survival rates of $89 \%$ (Simulation 1 , upper curve: Mintzer et al., 2013) and 86\% (Simulation 3, lower curve). The mean values and standard deviation of 1,00o model runs are shown. The upper curve represents the same model runs as in Fig. 2. No allowance was made for possible breeding depression at low population numbers. For clarity, only two of the six model runs are shown here, but the remaining four are close to the curves shown.

parameters, the long-term predictions of population size may not be accurate because circumstances are likely to change. Most importantly, the number of people using 
these waterways as a source of food and/or for transport, or whose activities pollute the water with sewage, noise and chemical or physical waste, is increasing. At the current rate, the human population of the state of Amazonas, which covers $22 \%$ of the Amazon basin, is expected to double every 79 years (IBGE, 2019). It is therefore likely that the number of gillnets, in which dolphins often drown, will increase, and that the density of fish, including those species that the dolphins feed on, will decrease. Although new dams are not planned for the area around Mamirauá, 227 new hydro-electric dams are planned for the Amazon basin as a whole (Castello \& Macedo, 2016; Forsberg et al., 2017), almost all of which can be expected to have a negative impact on river dolphins, directly or indirectly (Araújo \& Wang, 2015). As a consequence of these changes, annual survival rates of dolphins are likely to decrease. This model predicts that the impact of reducing annual survival by just $1 \%$ brings forward the point at which $95 \%$ of model iterations predict extinction to year 141 of the model run. If survival is reduced by $3 \%$ this happens in year 110 even if no breeding depression at low population levels is assumed. The equivalent figures with breeding depression are year 108 and 88, respectively.

Predicting when extinction is likely to occur is dependent upon a number of assumptions that cannot be tested, but the models leave no reasonable doubt that extinction will occur unless key population parameters improve. Reproductive characteristics are unlikely to be influenced by human-induced change at present, but survival rates can be. Although many different anthropogenic factors negatively affect boto populations, fishing practices cause the greatest damage. Botos are drowned in fishing nets, especially monofilament gillnets. Despite laws prohibiting it, they are also deliberately killed, especially for use as fish bait (da Silva et al., 2011; Iriarte \& Marmontel, 2013a,b; Brum et al., 2015). Enforcement of existing fishery laws throughout the species' range would increase its chances of survival. In addition, measures to reduce mortality in gillnets are necessary, particularly during the calving season. There is evidence to suggest that a large proportion of calves die in the first few months of life (Martin \& da Silva, 2018), and drowning because of entanglement in gillnets is probably a major contributor to this mortality. The peak of calving and early calf care in SeptemberNovember coincides with low water levels, when most botos are confined to edges of the main rivers and when high densities of large-mesh gillnets are set to catch fish there (Martin \& da Silva, 2018). Neonate botos are neither sufficiently experienced to avoid gillnets, nor strong enough to escape them once entangled. A single encounter with a gillnet during the first 3 months of life would thus likely be fatal.

Another important threat to the long-term survival of boto populations is the segmentation of rivers by dams across their range. These structures have profoundly damaging impacts on the ecological functioning of rivers (Lees et al., 2016; Forsberg et al., 2017), and harm dolphins by disrupting fish migration and preventing genetic exchange between dolphins either side of the dam. The scale of dam building planned for the Amazon basin (Forsberg et al., 2017), if realized, is likely to increase the rate of decline of botos and advance the date of their extinction.

Although the present population trajectory points towards extinction, there is still time to reverse the decline. Botos are still in sufficient abundance for reproduction to occur normally, and as yet relatively few rivers are dammed to the extent that animal movement is constrained, so genetic interchange is continuing. But the results of this study demonstrate that effective action must soon be taken by the range states of the Amazon river dolphin if this iconic animal is to survive. One important first step was taken by the government of Brazil: the banning of a commercial fishery for a scavenging catfish, the piracatinga Calophysus macropterus, for which large numbers of botos were killed for use as bait. This ban (IBAMA, 2014) commenced in 2015 for a 5-year period, and was largely, although not entirely, effective. Given the rate of decline of boto populations, the renewal of the ban on a permanent basis is crucial; a necessary, but not sufficient, measure to address anthropogenic dolphin mortality. Effective control of the use of the most damaging gillnet types will also be needed urgently if boto calves are to survive in sufficient numbers to replace adult losses.

Acknowledgements This study was part of Projeto Boto, a cooperative agreement between the National Amazon Research Institute (Instituto Nacional de Pesquisas da Amazônia; INPA/MCTIC) and the Mamirauá Sustainable Development Institute (MSDI-OS/MCTIC). We thank the many interns of Projeto Boto who contributed to data collection, and Admisson M. Carvalho, who participated in $90 \%$ of the surveys. Funding was provided by INPA/Ministério da Ciência, Tecnologia, Inovações e Comunicações (MCTIC), and Associação dos Amigos do Peixe-boi (AMPA)/Petrobras Socioambiental Program.

Author contributions Study design, fieldwork: ARM, VMFdS; data analysis, writing: ARM.

\section{Conflicts of interest None.}

Ethical standards The research abided by the Oryx guidelines on ethical standards, and was approved by the Ethical Standards Committee of the Brazilian Government Institute under which it was carried out (Instituto Nacional de Pesquisas da Amazônia, Manaus).

\section{References}

Araújo, C. \& WAng, J. (2015) The dammed river dolphins of Brazil: impacts and conservation. Oryx, 49, 17-24.

Braulik, G.T., Smith, B.D. \& Chaudhry, S. (2012) Platanista gangetica ssp. minor. In The IUCN Red List of Threatened Species 
2012. dx.doi.org/10.2305/IUCN.UK.2012.RLTS.T41757A17628296.en [accessed 27 March 2019].

Brum, S.M., Da Silva, V.M.F., Rossoni, F. \& Castello, L. (2015) Use of dolphins and caimans as bait for Calophysus macropterus (Lichtenstein, 1819) (Siluriforme: Pimelodidae) in the Amazon. Journal of Applied Ichthyology, 31, 675-68o.

Castello, L. \& Macedo, M.N. (2016) Large-scale degradation of the Amazon freshwater ecosystem. Global Change Biology, 22, 990-1007. DA Silva, V.M.F. (1994) Aspects of the Biology of the Amazonian dolphins genus Inia and Sotalia fluviatilis. PhD thesis, University of Cambridge, Cambridge, UK.

Da Silva, V.M.F., Freitas, C.E.C., Dias, R.L. \& Martin, A.R. (2018a) Both cetaceans in the Brazilian Amazon show sustained, profound population declines over two decades. PLOS ONE, 13, e0191304.

Da Silva, V.M.F., Martin, A.R. \& do Carmo, N.A.S. (2011) Amazonian fisheries pose threat to elusive dolphin species. Species, 53, 10-11.

da Silva, V., Trujillo, F., Martin, A., Zerbini, A.N., Crespo, E., Aliaga-Rossel, E. \& Reeves, R. (2018b) Inia geoffrensis. In The IUCN Red List of Threatened Species 2018. dx.doi.org/10.2305/IUCN UK.2018-2.RLTS.T10831A50358152.en [accessed 27 March 2019].

Forsberg, B.R., Melack, J.M., Dunne, T., Barthem, R.B., Goulding, M., Paiva, R.C.D. et al. (2017) The potential impact of new Andean dams on Amazon fluvial ecosystems. PLOS ONE, 12, e0182254.

Gravena, W., Farias, I.P., da Silva, M.N.F., da Silva, V.M.F. \& HRBEK, T. (2014) Looking to the past and the future: were the Madeira river rapids a geographical barrier to the boto (Cetacea: Iniidae)? Conservation Genetics, 15, 619-629.

Hrbek, T., da Silva, V.M.F., Dutra, N., Gravena, W., Martin, A.R. \& Farias, I.P. (2014) A new species of river dolphin from Brazil or: how little do we know our biodiversity. PLOS ONE, 9, e83623.

IB AMA (2014) Instrução Normativa Interministerial no o6/2014 Estabelece a Moratória da Pesca e Comercialização da Piracatinga em Águas de Jurisdição do Brasil e em Todo Território Nacional por um Período de Cinco Anos. Instituto Brasileiro do Meio Ambiente, Brasília, Brazil. ibama.gov.br [accessed 25 September 2019].

igBE (Instituto Brasileiro de Geografia e Estatística) (2019) Brasil/Amazonas, População. Brazilian Institute of Geography and Statistics, Rio de Janeiro, Brazil. cidades.ibge.gov.br/ brasil/am [accessed 15 February 2019].

Iriarte, V. \& Marmontel, M. (2013a) River dolphin (Inia geoffrensis, Sotalia fluviatilis) mortality events attributed to artisanal fisheries in the western Brazilian Amazon. Aquatic Mammals, 39, 116-124.

Iriarte, V. \& Marmontel, M. (2013b) Insights on the use of dolphins (boto, Inia geoffrensis and tucuxi, Sotalia fluviatilis) for bait in the piracatinga (Calophysus macropterus) fishery in the western
Brazilian Amazon. Journal of Cetacean Research and Management, $13,163-173$.

Lacy, R.C., Miller, P.S. \& Traylor-Holzer, K. (2015) Vortex 10 User's Manual. 15 April 2015 Update. IUCN SSC Conservation Breeding Specialist Group, and Chicago Zoological Society, Apple Valley, USA.

Lacy, R.C. \& Polla K, J.P. (2017) Vortex: A Stochastic Simulation of the Extinction Process. Version 10.3.5.o. Chicago Zoological Society, Brookfield, USA.

Lees, A.C., Peres, C.A., Fearnside, P.M., Schneider, M. \& ZuANON, J.S.A. (2016) Hydropower and the future of Amazonian biodiversity. Biodiversity Conservation, 25, 451-466.

Martin, A.R. \& Da Silva, V.M.F. (2018) Reproductive parameters of the Amazon river dolphin or boto Inia geoffrensis (Cetacea: Iniidae); an evolutionary outlier bucks no trends. Biological Journal of the Linnaean Society, 123, 666-676.

Mintzer, V.J., Martin, A.R., da Silva, V.M.F., Barbour, A.B., Lorenzen, K. \& Frazer, T.K. (2013) Effect of illegal harvest on apparent survival of Amazon river dolphins (Inia geoffrensis). Biological Conservation, 158, 280-286.

Moore, J.E., Martin, A.R. \& DA Silva, V.M.F. (2018) Intrinsic Growth (rmax) and Generation Time (T) Estimates for Inia geoffrensis, in Support of an IUCN Red List Re-assessment. U.S. Department of Commerce, NOAA Technical Memorandum NMFS-SWFSC-596. doi.org/10.7289/V5/TM-SWFSC-596 [accessed 21 May 2021].

Mosquera Guerra, F., Trujillo, F., Da Costa, M., Marmontel, M., Armenteras, D., Usma Oviedo, J. et al. (2018) Movements and Habitat Use of River Dolphins (Cetartiodactyla: Iniiidae) in the Amazon and Orinoco River Basins, Determined from Satellite Tagging. Paper SC/67B/SM/14 submitted to the Scientific Committee of the International Whaling Commission. International Whaling Commission, Cambridge, UK.

Reeves, R.R. \& Martin, A.R. (2018) River dolphins. In Encyclopedia of Marine Mammals, 3rd edition (eds B. Würsig, J.G.M. Thewissen \& K.M. Kovacs), pp. 827-829. Academic Press, London, UK.

Siciliano, S., Valiati, V.H., Emin-Lima, R., Costa, A.F., Sartor, J., Dorneles, T. et al. (2016) New genetic data extend the range of river dolphins Inia in the Amazon delta. Hydrobiologia, 777, 255-269.

Smith, B.D., Braulik, G.T. \& Sinha, R. (2012) Platanista gangetica ssp. gangetica. In The IUCN Red List of Threatened Species 2012. dx.doi.org/10.2305/IUCN.UK.2012.RLTS.T41756A17627639.en [accessed 27 March 2019].

Turvey, S.T., Pitman, R.L., Taylor, B.L., Barlow, J., Akamatsu, T., BARRetT, L.A. et al. (2007) First human-caused extinction of a cetacean species? Biology Letters, 3, 537-540. 